\title{
Plasma $\beta$-Endorphin in Perinatal Asphyxia and Respiratory Difficulties in Newborn Infants
}

\author{
VINETA RUTH, MAIJA POHJAVUORI, LIISA ROVAMO, KATARIINA SALMINEN, AND \\ TIMO LAATIKAINEN \\ Departments I and II of Obstetrics and Gynecology and the Children's Hospital, University of Helsinki, \\ Helsinki, Finland
}

\begin{abstract}
The effects of intrauterine stress and birth asphyxia on the plasma concentration of $\beta$-endorphin $(\beta-$ $\mathrm{E})$ in cord blood and in venous blood at the age of $2 \mathrm{~h}$ was investigated in newborn infants. Term infants with acute birth asphyxia $(n=11)$, infants born to mothers with preeclampsia $(n=15)$, and prematures with respiratory difficulties $(n=4)$ were entered into the study. Twenty control infants were studied; 12 were born after spontaneous delivery and eight after elective cesarean section. After normal spontaneous delivery, the plasma $\beta$-E level decreased significantly, the median values being $17 \mathrm{pmol} /$ liter at birth and $9.3 \mathrm{pmol} / \mathrm{liter}$ at the age of $2 \mathrm{~h}$, whereas after elective cesarean section it remained unchanged (13 and $13 \mathrm{pmol} / \mathrm{liter}$, respectively). In acute asphyxia the plasma $\beta$-E level varied widely at birth, from 9.7 to 108 $\mathrm{pmol} / \mathrm{liter}$. At the age of $2 \mathrm{~h}$, the $\beta$-E level was high ( 26 to $83 \mathrm{pmol} / \mathrm{liter}$ ) in those asphyctic infants who required prolonged mechanical ventilation, but it fell to the range of 1.6-13 pmol/liter when the infant recovered rapidly. The $\beta$-E level was not increased in the preeclampsia group, not even in small for gestational age infants. In preterm newborn infants with respiratory difficulties, a significant postnatal rise of plasma $\beta$-E level was found, the $\beta$-E value varying from 7.3 to $16 \mathrm{pmol} /$ liter at birth and from 61 to $168 \mathrm{pmol} / \mathrm{liter}$ at the age of $2 \mathrm{~h}$. These results indicate that increased $\beta-\mathrm{E}$ secretion is associated with respiratory difficulties in the newborn infant. (Pediatr Res 20: 577-580, 1986)
\end{abstract}

Abbreviation

$$
\beta \text {-E, } \beta \text {-endorphin }
$$

The pituitary gland secretes $\beta$-E concomitantly with $\beta$-lipotropin and corticotropin (1), and the secretion increases, e.g. in physical exercise (2) and during labor $(3,4)$. Acute birth asphyxia has been found to increase plasma $\beta$-E concentration in umbilical cord blood $(5,6)$. After birth, plasma level of $\beta$-E is higher in newborn infants than in adults $(7,8)$ but the role of this increased $\beta$-E secretion in the early neonatal period is unclear. The effects of $\beta$-E in newborn infants has been studied by administration of naloxone, a potent opioid receptor blocking agent. In rabbits naloxone has been found to reverse postnatal depression caused

Received November 1, 1985; accepted February 11, 1986.

Correspondence Timo Laatikainen, M.D., Departments of Obstetrics and Gynecology, Helsinki University General Hospital, Haartmaninkatu Z, SF-00290 Helsinki, Finland.

This work was supported by grants from the Academy of Finland, The Sigrid Juselius Foundation, Finska Läkaresällskapet, The Signe and Ane Gyllenberg Foundation, and The Foundation for Pediatric Research. by fetal asphyxia (9). In newborn infants, naloxone reduced the decrease in ventilation induced by hypoxia (10). These findings suggest that increased endorphin activity plays a role in fetal distress and in neonatal respiratory difficulties.

Data available on the relationshop between neonatal disorders and plasma $\beta$-E level are very limited (5-8). The aim of the present study was to evaluate if the newborn infant responds with $\beta$-E secretion to chronic placental insufficiency, acute birth asphyxia, and neonatal respiratory difficulties.

\section{MATERIALS AND METHODS}

Subjects. Thirty patients and 20 control infants were selected for the study. The birth asphyxia group consisted of 11 term infants with acute birth asphyxia, born after normal pregnancy and spontaneous labor (group A). Fetal cardiotocography had shown abnormal findings: late or variable decelerations or slow fetal heart rate (below $100 \mathrm{bpm}$ for at least $5 \mathrm{~min}$ ). The criterion for enrolling in the study was an Apgar score of 6 or less at 1 $\min (n=6)$, or an umbilical cord arterial $\mathrm{pH}$ of 7.05 or less $(n$ $=5$ ). Their mean birth weight was $3740 \pm 627$ (SD) g, being appropriate for gestational age in 10 infants. One infant was large for date. Immediately after birth eight infants needed mechanical ventilation (cases $1-8$, Table 1), and four (cases 1-4) still required it at the age of $2 \mathrm{~h}$. Two infants (nos. 5 and 6) had tachypnea, defined as a respiration rate over $60 / \mathrm{min}$ and an $\mathrm{FrO}_{2}$ of over 0.30 . The remaining five infants did not shown any respiratory difficulties at the age of $2 \mathrm{~h}$. Blood $\mathrm{pH}$ was below 7.25 in three infants (cases 1, 3, and 9) at the age of $2 \mathrm{~h}$. Case 1 died on the lst day due to septicaemia.

Infants born to mothers with preeclampsia were selected as a risk group with respect to chronic placental insufficiency and intrauterine asphyxia (group B). The criterion for enrolling in the study was maternal blood pressure over $140 / 90 \mathrm{~mm} \mathrm{Hg}$ with proteinuria $(>1 \mathrm{~g} /$ day). All the 15 infants were delivered by elective cesarean section, and 11 infants were born prematurely. The indication for cesarean section was an abnormal fetal heart rate in seven cases (nos. 1 and 4-7, 9, 10; Table 2) and severe preeclampsia in the remaining eight cases. The birth weights of eight infants were appropriate for the gestational ages, and of seven infants below -2 SD (11), Only one infant (no. 2) needed assisted ventilation immediatly after birth and no infant needed it at the age of $2 \mathrm{~h}$. Five infants (cases $1-3,6,9$ ) had tachypnea. In all cases blood pH exceeded 7.25 at the age of $2 \mathrm{~h}$.

Four appropriate for gestational age premature infants, born at 27-32 wk of gestation, and developing respiratory difficulties, were included in the study (group C). They were all delivered by elective cesarean section, because of polyhydramnion in a twin pregnancy (cases 1 and 2, Table 2) and premature rupture of membranes in cases 3 and 4 . Infants 1 and 2 needed assisted ventilation immediately after birth and at the age of $2 \mathrm{~h}$ because of hyaline membrane disease, while infants 3 and 4 developed 
tachypnea. The blood $\mathrm{pH}$ was normal in all infants at the age of $2 \mathrm{~h}$. The brains of all study subjects were examined by ultrasonography and no intracranial hemorrhage was found.

Control infants. In order to reveal any possible effect of the mode of delivery on the neonatal plasma concentration of $\beta$-E, 20 term appropriate for gestational age infants were also studied: 12 infants were born spontaneously by the vaginal route with a mean gestational age of $39.7 \pm 1.4( \pm$ SD) wk. Eight infants were delivered by elective cesarean section under epidural anesthesia because of breech presentation or contracted pelvis; the mean gestational age of these infants was $39.1 \pm 0.7 \mathrm{wk}$. All these 20 pregnancies were uncomplicated, and cardiotocography did not reveal any abnormal findings antenatally or during labor. The Apgar score at the age of 1 min varied from 8 to 10 , and the umbilical arterial blood $\mathrm{pH}$ was 7.18 or more which was considered to be normal. Their postnatal condition was good.

Collection of blood samples. Immediately after birth, the umbilical cord was clamped at the maternal and fetal ends, and the arterial and venous blood was separately aspirated into heparin-

Table 1. Plasma concentrations of $\beta-E$ in term newborn infants with acute birth asphyxia

\begin{tabular}{|c|c|c|c|c|}
\hline \multirow[b]{2}{*}{ Infant } & \multirow{2}{*}{$\begin{array}{c}\text { Apgar } \\
\text { score } \\
(1 / 5 \mathrm{~min})\end{array}$} & \multirow{2}{*}{$\begin{array}{l}\text { Cord } \\
\text { arterial } \\
\text { pH }\end{array}$} & \multicolumn{2}{|c|}{$\beta$-E (pmol/liter) } \\
\hline & & & $\begin{array}{l}\text { Cord } \\
\text { venous }\end{array}$ & $\begin{array}{c}\text { At the age } \\
\text { of } 2 \mathrm{~h}\end{array}$ \\
\hline 1 & $1 / 2$ & 6.97 & 108 & 83 \\
\hline 2 & $0 / 3$ & 7.16 & 74 & 30 \\
\hline 3 & $6 / 7$ & 7.11 & 37 & 29 \\
\hline 4 & $3 / 5$ & 7.11 & 18 & 26 \\
\hline 5 & $1 / 6$ & 7.29 & 10 & 10 \\
\hline 6 & $6 / 10$ & 6.95 & 9.7 & 11 \\
\hline 7 & $2 / 8$ & 7.03 & 25 & 2.1 \\
\hline 8 & $4 / 6$ & 7.24 & 11 & 3.7 \\
\hline 9 & $7 / 9$ & 7.05 & 38 & 13 \\
\hline 10 & $7 / 9$ & 7.04 & 17 & 1.6 \\
\hline 11 & $5 / 9$ & 7.09 & 21 & 7.3 \\
\hline
\end{tabular}

ized syringes. Blood gas analysis was done in arterial blood within $10 \mathrm{~min}$. For the $\beta$-E assay, 3-5 ml of venous blood was collected in polyethylene tubes containing $5 \mu \mathrm{l}$ of heparin and $25 \mu \mathrm{l}$ of a protease inhibitor, aprotinin, per $1 \mathrm{ml}$ of blood. The tubes were centrifuged at $+5^{\circ} \mathrm{C}$, and the plasma was stored at $-18^{\circ} \mathrm{C}$ until analyzed. A venous blood sample was taken from the infant at the age of $2 \mathrm{~h}$ for $\beta$-E assay and for blood gas analysis.

$\beta$-E endorphin assay. A specific $\beta$-E assay was used as described in detail previously (12). $\beta$-E was completely separated from $\beta$ lipotropin and other cross-reacting endorphins by cation-exchange liquid chromatography. The fraction containing $\beta$-E was lyophilized and subjected to radioimmunoassay. The mean recovery of $\beta-E$ added to the plasma sample and carried through the procedure was $63 \%$. The results were corrected for procedural losses. The coefficient of variation of replicate determinations of $\beta$-E was $13 \%$.

Statistical analysis. The distribution of $\beta$-E values was skew and therefore logarithmic transformation was used before statistical analysis. Student's $t$ test, the two-sample Wilcoxon test, and regression analysis were used in statistical calculations.

The study protocol was approved by the Ethics Committee of the Departments of Obstetrics and Gynecology and by the Children's Hospital. Before entry, informed consent was obtained from the mother.

\section{RESULTS}

In the control infants (Fig. 1) the median concentration of $\beta$ $E$ in the umbilical venous blood was $17 \mathrm{pmol} /$ liter (range 5.1$59 \mathrm{pmol} / \mathrm{liter})$ after spontaneous delivery and $13 \mathrm{pmol} /$ liter $(6.8$ $23 \mathrm{pmol} /$ liter) after elective cesarean section. At the age of $2 \mathrm{~h}$, the median $\beta$-E values (ranges) were $9.3(4.2-16)$ and 13 (7.936) $\mathrm{pmol} / \mathrm{liter}$, respectively. No statistically significant differences were found between the groups at birth or at the age of 2 $h$. However, the postnatal change of plasma $\beta$-E levels showed a significantly different pattern between these groups. In the vaginal delivery group the plasma $\beta$-E level decreased significantly $(p<0.01)$, whereas no change was found after elective cesarean section.

Table 2. Plasma concentrations of $\beta$-E in newborn infants born to mothers with preeclampsia (group B) and in preterm infants with respiratory difficulties (group $C$ )

\begin{tabular}{|c|c|c|c|c|c|c|}
\hline \multirow[b]{2}{*}{ Infant } & \multirow[b]{2}{*}{$\begin{array}{c}\text { Gestational age } \\
\text { (wk) }\end{array}$} & \multirow[b]{2}{*}{ Wt (g) } & \multirow[b]{2}{*}{$\begin{array}{l}\text { Apgar score } \\
\text { at } 1 \mathrm{~min}\end{array}$} & \multirow[b]{2}{*}{$\begin{array}{c}\text { Cord arterial } \\
\mathrm{pH}\end{array}$} & \multicolumn{2}{|c|}{$\beta$-E (pmol/liter) } \\
\hline & & & & & Cord venous & $\begin{array}{c}\text { At the age } \\
\text { of } 2 \mathrm{~h}\end{array}$ \\
\hline \multicolumn{7}{|l|}{ Group B } \\
\hline 1 & 31 & 1120 & 8 & 7.15 & 38 & 17 \\
\hline 2 & 32 & 1795 & 5 & 7.26 & 2.0 & 18 \\
\hline 3 & 32 & 1790 & 8 & 7.30 & 2.2 & 5.3 \\
\hline 4 & 32 & 1550 & 7 & 7.09 & 27 & 14.2 \\
\hline 5 & 33 & 1870 & 9 & 7.22 & 8.5 & 6.4 \\
\hline 6 & 33 & 1550 & 8 & 7.21 & 7.0 & 11.6 \\
\hline 7 & 33 & 1350 & 8 & 7.21 & 8.2 & 25.7 \\
\hline 8 & 34 & 1880 & 8 & 7.20 & 2.8 & 14.4 \\
\hline 9 & 35 & 1400 & 8 & 7.34 & 12 & 32 \\
\hline 10 & 35 & 1690 & 8 & 7.19 & 6.8 & 6.9 \\
\hline 11 & 35 & 2400 & 8 & 7.39 & 10.7 & 15 \\
\hline 12 & 37 & 2230 & 8 & 7.28 & 9.7 & 17.6 \\
\hline 13 & 37 & 1640 & 8 & 7.25 & 11.5 & 2.8 \\
\hline 14 & 37 & 2225 & 10 & 7.31 & 6.8 & 9.1 \\
\hline 15 & 37 & 2460 & 9 & 7.32 & 3.1 & 18.3 \\
\hline \multicolumn{7}{|l|}{ Group C } \\
\hline 1 & 27 & 1125 & 5 & 7.29 & 16 & 168 \\
\hline 2 & 27 & 840 & 1 & 7.33 & 7.3 & 61 \\
\hline 3 & 32 & 1800 & 7 & ND* & 8.4 & 140 \\
\hline 4 & 32 & 2270 & 7 & ND & 11 & 74 \\
\hline
\end{tabular}

* Not determined. 


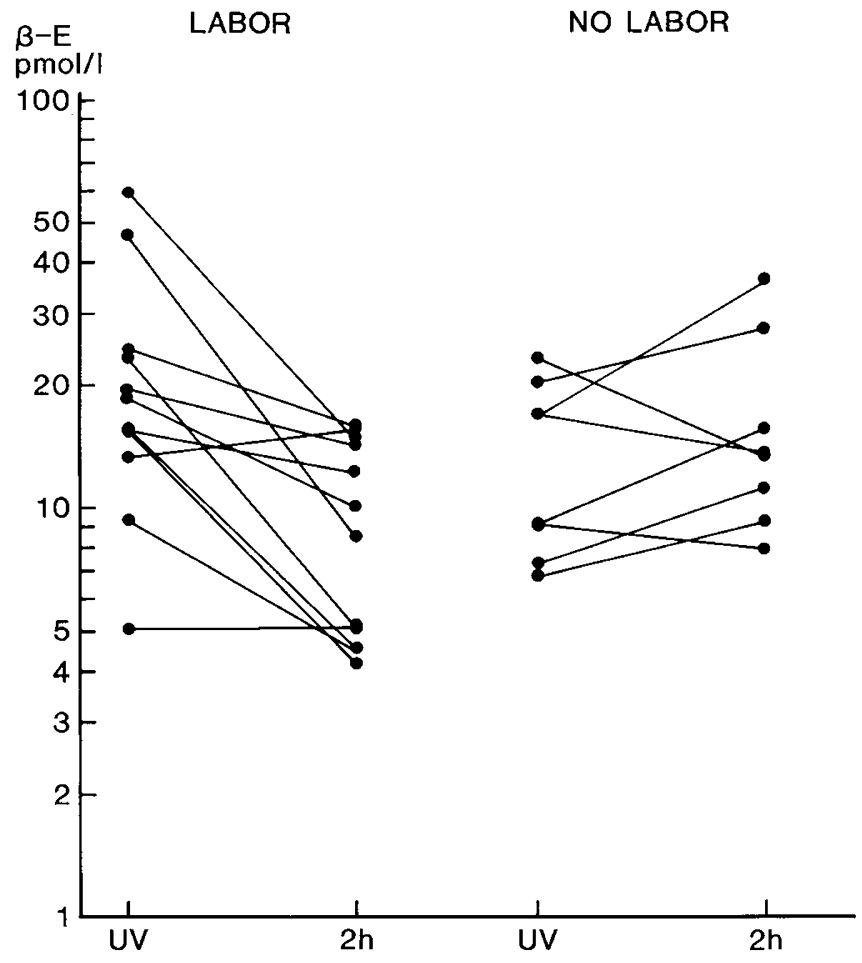

Fig. 1. Plasma concentrations of $\beta$ - $\mathrm{E}$ at birth and at the age of $2 \mathrm{~h}$ in newborns after normal spontaneous delivery by the vaginal route and after elective cesarean section under epidural anesthesia.

In the infants with acute birth asphyxia (group A, Fig. 2) the median $\beta$-E level was $21 \mathrm{pmol} /$ liter at birth and $11 \mathrm{pmol} /$ liter at the age of $2 \mathrm{~h}$. No statistically significant difference was found in the cord $\beta$-E level between the asphyctic and the control infants delivered by the vaginal route. The postnatal change showed a similar decrease in the five infants (nos. 7-11, Table 1) without respiratory difficulties as in the controls. However, the six infants with respiratory difficulties differed in their postnatal changes of $\beta$-E level from the five infants with normal respiration $(p<0.02)$ as well as from the controls $(p<0.001)$. In the four infants (nos. 1-4, Table 1) who needed prolonged assisted ventilation, plasma $\beta$-E level at the age of $2 \mathrm{~h}$ exceeded the mean $+2 \mathrm{SD}$ of the controls, whereas no postnatal change was found in the two tachypneic infants (nos. 5 and 6).

In the asphyctic infants, no significant correlation between the cord plasma level of $\beta-\mathrm{E}$ and the 1-min Apgar score was found (Table 1). A negative correlation was found between the cord plasma level of $\beta$-E and the 5-min Apgar score $(r=-0.60, p<$ $0.05)$. No significant correlation was found between $\mathrm{pH}$ and the $\beta$-E level in cord blood, but at the age of $2 \mathrm{~h}$, there was a negative correlation between $\mathrm{pH}$ and $\beta$-E level $(r=-0.73, p<0.01)$.

In the infants born after preeclampsia pregnancy (group B), Fig. 2), the median $\beta$-E level was $8.1 \mathrm{pmol} /$ liter at birth and 14 $\mathrm{pmol} /$ liter at the age of $2 \mathrm{~h}$ (Table 2). No significant differences were found at birth or at the age of $2 \mathrm{~h}$ between the preeclampsia group and the control infants delivered by elective cesarean section. Postnatal changes of $\beta$-E levels showed a great individual variation, with an increase in four (nos. $2,3,6$, and 9) of the five infants with tachypnea. The plasma $\beta$-E level did not differ between the seven small for gestational age infants and the remaining eight appropriate for gestational age infants at birth or at the age of $2 \mathrm{~h}$. There was no correlation between $\beta$-E and $\mathrm{pH}$, neither did the cord $\beta-\mathrm{E}$ level correlate with Apgar score or gestational age.

In the preterm newborn infants (group C, Fig. 2) with respiratory difficulties the median $\beta$-E level was $9.6 \mathrm{pmol} /$ liter at birth and $94 \mathrm{pmol} /$ liter at the age of $2 \mathrm{~h}$. $\beta$-E levels at birth were

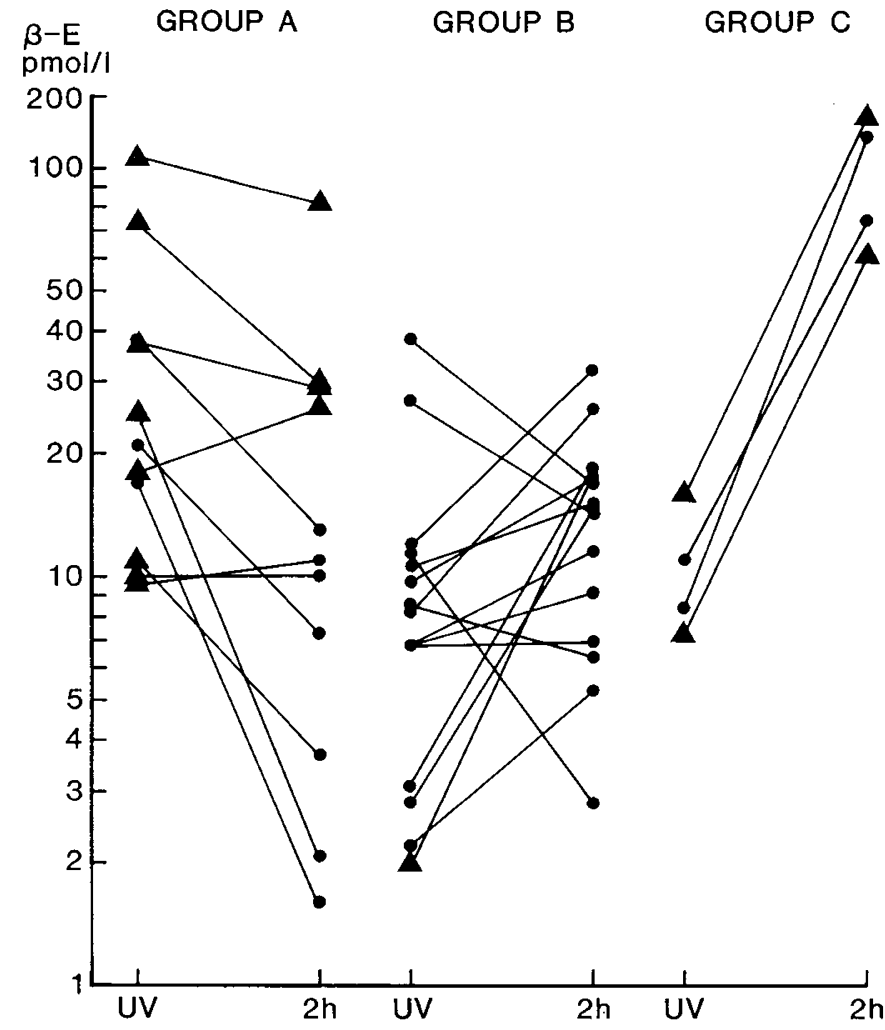

Fig. 2. Postnatal changes of plasma $\beta$-E levels in infants born with birth asphyxia (group A), after preeclamptic pregnancy (group B), and in prematures with respiratory difficulties (group C), $\mathbf{\Lambda}$, assisted ventilation needed; $\bullet$, no ventilatory assistance; $U V$, the umbilical venous sample; $Z h$, the sample taken at the age of $2 \mathrm{~h}$.

similar to those in the term control infants delivered by cesarean section, but had increased at the age of $2 \mathrm{~h}$ significantly, exceeding the mean $+2 \mathrm{SD}$ (42 pmol/liter) of the controls.

\section{DISCUSSION}

We determined $\beta$-E with a specific method where other crossreacting endorphins, e.g. $\beta$-lipotropin, $\alpha$ - and $\gamma$-endorphin, were first separated by liquid chromatography before radioimmunoassay (12). In most of the newborn infants studied at the age of $2 \mathrm{~h}$ the $\beta$-E level exceeded the mean value in the adults $(4 \pm 0.6$, $\mathrm{SE})$ with a greater individual variation than in adults. The coefficient of variation of replicate determinations of $\beta$-E in plasma was $13 \%$. This implies, that the great variation in the plasma $\beta$-E level among the infants studied is individual rather than methodological. We used cord venous blood for the $\beta$-E assay, because we were not able to obtain a sufficient amount of cord arterial blood. In one earlier study $\beta$-E level was found to be higher in cord arterial than in cord venous blood (5), whereas in several other studies no significant differences were found $(6$, $7,13,14)$. These findings suggest that the placenta does not seem to supply any significant amount of $\beta$-E into the fetal circulation, although $\beta$-E has been found in the placenta $(15,16)$. A good correlation between cord venous and arterial $\beta$-E level has been found (6) suggesting that cord arterial level of $\beta$-E may not reflect better fetal $\beta$-E than cord venous level. A great increase of $\beta$-E concentration in the maternal circulation occurs during labor (3, 4 ), but this $\beta$-E probably does not cross the placenta. No data are available on the possible transplacental passage of $\beta-\mathrm{E}$, but a closely related peptide, corticotropin, was not found to cross the placental barrier (17). The fetal pituitary contains large amount of $\beta$-E $(18,19)$ and is the most likely source of $\beta-\mathrm{E}$ in the fetoplacental circulation. 
In contrast to the results of Wardlaw et al. (5), no significant negative correlation between $\mathrm{pH}$ and the plasma $\beta$-E level in cord blood was demonstrated. However, such a correlation was found in asphyctic infants at the age of $2 \mathrm{~h}$, but only three of 11 infants had acidosis. In the control infants without asphyxia, the mode of delivery modified the change of neonatal $\beta$-E levels (Fig. $1)$. These results suggest that there are other factors not related to asphyxia which influence the plasma $\beta$-E level in newborn infants. Increased immunoreactivity of $\beta$-E was reported in amniotic fluid in pregnancies associated with intrauterine growth retardation (20), but this could not be confirmed in a later study (21). In the present study, chronic placental insufficiency with intrauterine growth retardation was not associated with increased release of $\beta$-E into the fetoplacental circulation.

We found that in healthy control infants the plasma $\beta$-E level decreased significantly after spontaneous vaginal delivery (Fig. 1) as well as in asphyctic infants who recovered rapdily and did not have any respiratory difficulties (Fig. 2). In all infants who needed mechanical ventilation at the age of $2 \mathrm{~h}$, the plasma $\beta$-E level exceeded the upper normal limit calculated in the control group of healthy infants at that age. Moreover, the evidence of sustained $\beta$-E release was also found in term infants who developed tachypnea. This shows that respiratory difficulties are associated with increased $\beta$-E release in the early neonatal period. Severe and prolonged asphyxia in these infants was probably an initiating factor, explaining the inverse correlation between the $\beta$-E level and $\mathrm{pH}$ at the age of $2 \mathrm{~h}$.

In the preterm infants with respiratory difficulties, we found a 10 -fold postnatal increase in the $\beta$-E level (Fig. 2). A less significant increase was found in four of five infants with mild tachypnea in the preeclampsia group. Chronic placental insufficiency may, however, decrease the capacity of the pituitary gland to secrete $\beta$-E after birth. We and Moss et al. (7) did not find any correlation between gestational age and plasma $\beta$-E level at birth or in the early neonatal period. In cerebrospinal fluid, high concentrations of $\beta$-E immunoreactivity have been reported in prematures and tachypnea or hyaline membrane disease, and comparison between premature and term infants did not reveal any significant difference (22). These findings suggest that respiratory difficulties rather than prematurity are associated with the increase of postnatal $\beta$-E secretion in premature infants.

The localization of opiate receptors in the central nervous system suggests that endogenous opioid peptides take part in the regulation of vagal reflexes and pain sensitivity (23). Injection of $\beta$-E into the central nervous system of dogs resulted in marked respiratory depression (24). On the other hand, naloxone was found to reduce the respiratory depression in hypoxic newborns (10). These findings suggest that the site of $\beta$-E action on respiration is the respiratory center. An association between elevated plasma level of $\beta-\mathrm{E}$ and respiratory disorders in the newborn infant was found in the present study. However, it is unclear whether increased release of $\beta$-E into the blood circulation reflects the level of the central nervous system, because $\beta$-E penetrates the blood-brain barrier poorly (25). However, elevated concentrations of $\beta$-E immunoreactivity have been reported in newborn cerebrospinal fluid in asphyxia and in premature infants with apnea $(22,25)$. We speculate that increased $\beta$-E secretion after birth might depress ventilation. However, the stimuli to this increased secretion remained unclear.

\section{REFERENCES}

1. Guillemin R, Vargo T, Rossier J, Minick E, Ling N, Rivier C, Vale W, Bloom $F 1977 \beta$-EP and adrenocorticotropin are secreted concomitantly by the pituitary gland. Science 197:1367-1369

2. Carr DB, Bullen BA, Skrinar GS, Arnold MA, Rosenblatt M, Beitins IZ, Martin JB, McArthur JW 1981 Physical conditioning facilitates the exerciseinduced secretion of beta-endorphin and beta-lipotropin in women. $\mathrm{N}$ Engl J Med 305:560-563

3. Facchinetti F, Bagnoli F, Petraglia F, Parrini D, Sardelli S, Genazzani AR 1982 Fetomaternal opioid levels and parturition. Obstet Gynecol 62:764-768

4. Räisänen I, Paatero H, Salminen K, Laatikainen T 1984 Pain and plasma $\beta$ endorphin level during labor. Obstet Gynecol 64:783-786

5. Wardlaw SL, Stark RI, Baxi L, Frantz AG 1979 Plasma $\beta$-endorphin and $\beta$ lipotropin in the human fetus at the delivery: correlation with arterial $\mathrm{pH}$ and $\mathrm{pO}_{2}$. J Clin Endocrinol Metab 49:888-891

6. Shaaban MM, Hung TT, Hoffman DI, Lobo RA, Goebelsmann U $1982 \beta$ Endorphin and $\beta$-lipotropin concentrations in umbilical cord blood. Am $\mathbf{J}$ Obstet Gynecol 144:560-568

7. Moss IR, Conner H, Yee WFH, lorio P, Scarpelli EM 1982 Human $\beta$ endorphin-like immunoreactivity in the perinatal/neontal period. J Pediatr 101:443-446

8. Facchinetti F, Bagnoli F, Bracci R, Genazzani R 1982 Plasma opioids in the first hours of life. Pediatr Res 16:95-98

9. Chernick V, Graig RJ 1982 Naloxone reverses neonatal depression caused by fetal asphyxia. Science 216:1252-1253

10. Boeck C De, Reempts P van, Rigatto H, Chernick V 1984 Naloxone reduces decrease in ventilation induced by hypoxia in newborn infants. $J$ Appl Physiol 56:1507-1511

11. Usher R, McLean F 1969 Intrauterine growth of live-born Caucasian infants at sea level: standard obtained from measurements in 7 dimensions of infants born between 25 and 44 weeks of gestation. J Pediatr 74:901-910

12. Laatikainen T, Salminen K, Stenman U-H, Leppäluoto J 1985 Determination of plasma $\beta$-endorphin and $\beta$-lipotropin by cation-exchange liquid chromatography and radioimmunoassay. Clin Chem 31:134-136

13. Csontos K, Rust M, Höllt V, Mahr W, Kromer W, Toschemacher HJ (1979) Elevated plasma $\beta$-endorphin levels in pregnant women and their neonates. Life Sci 25:835-844

14. Räisänen I, Paatero H, Salminen K, Laatikainen T 1985 Maternal and fetal plasma levels of $\beta$-E at elective cesarean section and after spontaneous labor. Obstet Gynecol (in press)

15. Nakai Y, Nakao K, Oki S, Imura H 1978 Presence of immunoreactive $\beta$ lipotropin and $\beta$-endorphin in human placenta. Life Sci 23:2013-2018

16. Liotta AS, Houghten R, Krieger DT 1982 Identification of a $\beta$-endorphin-like peptide in cultured human placental cells. Nature 295:593-595

17. Miyakawa I, Ikeda I, Maeyama M 1974 Transport of ACTH across human placenta. J Clin Endocrinol Metab 39:440-442

18. Brubaker PL, Baird AC, Bennett HPJ, Browne CA, Solomon S 1982 Corticotropic peptides in the human fetal pituitary. Endocrinology 111:1150-1155

19. Vuolteenaho O, Leppäluoto J, Höyhtyä M, Hirvonen J 1983 endorphin-like peptides in autopsy pituitaries from adults, neonates and foetuses. Acta Endocrinol 102:27-34

20. Divers WA, Stewart RD, Wilkes MM, Yen SSC 1982 Amniotic fluid $\beta$ endorphin and $\beta$-melanocyte-stimulating hormone immunoreactivity in normal and complicated pregnancies. Am J Obstet Gynecol 144:539-542

21. Petrucha RA, Goebelsmann U, Hung TT, Haase HR, Lobo RA 1983 Amniotic fluid $\beta$-endorphin and $\beta$-lipotropin concentrations during the second and third trimesters. Am J Obstet Gynecol 146:644-651

22. Burnard ED, Todd DA, John E, Hindmarsh KW 1982 Beta-endorphin levels in newborn cerebrospinal fluid. Aust Paediatr J 18:258-263

23. Snyder SH 1977 Opiate receptors in the brain. N Engl J Med 296:266-271

24. Moss IR, Friedman E $1978 \beta$-Endorphin: effects on respiratory regulation. Life Sci 23:1271-1276

25. Meisenberg G, Simmons WH 1983 Minireview. Peptides and the blood-brain barrier. Life Sci 32:2611-2623

26. Laungani SG, Delivoria B, Gintzler A, Wong S, Glass L 1985 Apgar scores and cerebrospinal fluid $\beta$-endorphin-like immunoreactivity during the first day of life. Am J Dis Child 139:403-404 